\title{
Strategic prospects for the development of world energy
}

\author{
Tatiana Meshcheryakova ${ }^{1, *}$ \\ ${ }^{1}$ Moscow State University of Civil Engineering, 129337, 26, Yaroslavskoye Shosse, Moscow, Russia
}

\begin{abstract}
Oil is one of the key primary energy resources in the global fuel and energy balance, and experts predict that it will remain so until 2040 . However, right now the oil industry is undergoing a period of structural changes. On the one hand, the instability of the world economy, as well as inter-country conflicts, the policy of trade wars and sanctions create excessive volatility in the commodity and financial oil markets. On the other hand, the development of renewable energy, the hydrogen economy and the gas fuel market, as well as increasing environmental requirements, pose a new challenge to the oil market. All these issues determine the key aspects of the energy complex, the system analysis and management of which should be focused on the implementation of the concept of sustainable development of the global economy. The article provides an assessment of the prospects for the development of global energy, taking into account the above trends.
\end{abstract}

\section{Introduction}

Population growth defines new energy needs. $80 \%$ of the world's population consumes more energy than is necessary to achieve the human development index in the developed world. The solution to the problems of ensuring the stability of energy supply is a catalyst for the rise in prices for it. Changes in energy prices are changing approaches to managing investment projects in the energy field. Infrastructure development needs, including energy storage systems, must be considered. Information and technology is distributed everywhere determining the development of many industries, including energy and related activities, allowing the creation of conditions for the development of energy infrastructure.

In the development of an energy-efficient environmental global economy, an important aspect is the regulation of energy corporations. At the moment, corporations carry out free hydrocarbon emissions, providing the population with energy needs and changing the climate. Questions arise regarding the reduction of energy consumption and the determination of emission charges. It should also be borne in mind that most of the emissions are produced by transport, which requires a change in the lifestyle of the population.

\footnotetext{
*Corresponding author: meshcheryakovats@mgsu.ru
} 
Existing restrictions and risks should not impede the economic development of countries. Without reducing the standard of living of the population, it is necessary to create favorable conditions for the economic development of countries.

World experience indicates the need to increase energy potential, providing the necessary quality of life for society.

A colossal breakthrough was achieved in India, where the grid became very rapidly developed. And in African countries there is a big problem of energy supply of the population. The development of cities on the African continent led to the fact that more than 300 million people became residents of cities, which required new approaches to providing energy. The discovered gas fields in Africa can become an opportunity for the development of countries both through self-sufficiency in energy resources and through exports.

It is important to take into account the trend towards diversification of energy resources. The energy market is currently characterized by low energy prices. It is expected $\$ 50-55$ per barrel of oil, and possibly even lower by $\$ 6$. There is a conflict of paradigms associated with the cost of resources and restrictions on energy consumption.

According to many experts, the transition to renewable energy can reduce the standard of living of the population and reduce the rate of economic growth of many countries.

The object of research is the energy market.

The subject of the study is to ensure the sustainable development of the world economy.

The purpose of the study is to assess the prospects for the development of world energy, taking into account existing trends and challenges.

To achieve this goal, the following tasks were solved:

- will analyze the development trends of the global energy market;

- considered alliances in the energy market;

- Key factors of competitiveness in the energy sector are presented.

\section{Materials and Methods}

As an information basis, data from expert and rating agencies are used.

Long-term forecasts in the field of energy are carried out by British Petroleum (BP), which conducts large-scale studies and allows us to assess development prospects and threats. These forecasts are presented in the annual edition of BP Energy Outlook.

Data on energy consumption scenarios, depending on the implementation of measures to contain processes that affect climatic conditions, are based on materials from the S\&P Global rating agency.

One of the most important sources of information on environmental aspects in the energy sector is the International Renewable Energy Agency (IRENA). This agency has a large statistical database of ongoing renewable energy projects and has its own energy forecasts.

In the research process, a factor analysis was used, which contains the following iterations: determining the purpose of the study and setting tasks that need to be solved; a selection of factors determining the studied effective indicators was carried out; causeeffect relationships between factors and an effective indicator in the global energy sector are determined.

\section{Results}

The growth of the population and its needs determines the increase in demand for energy resources. This is confirmed by the results of the BP (Figure 1) [1]. 


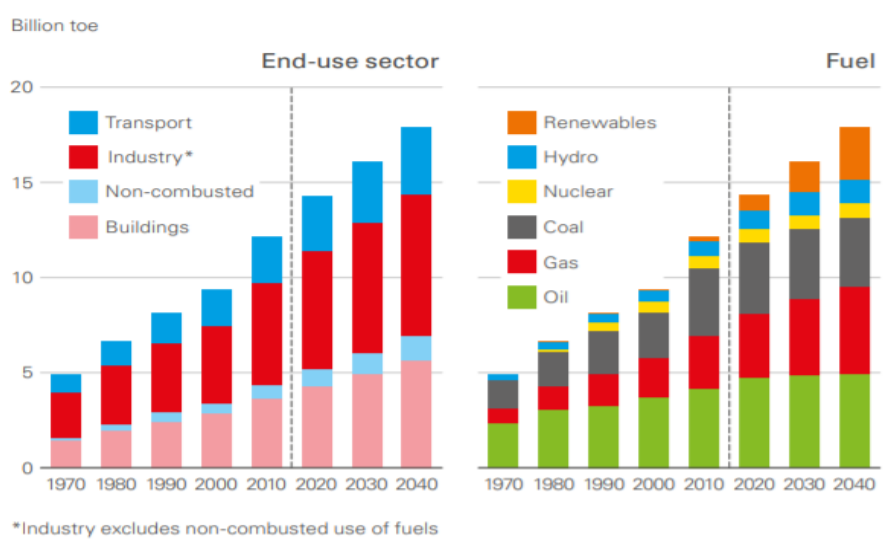

Fig. 1. The Outlook considers the energy transition through three different lenses: sectors and fuels.

The development of global energy should take into account the problems of transition to cleaner technologies. Oil and gas are not essentially harmful products. Negative consequences are emissions from their burning. To solve pollution problems, it is necessary to use hydrogen or use new technologies for purification of combustion products from carbon impurities [2-5]. All countries that have ratified the Paris Agreement are ready to go towards the goal of preventing an annual temperature increase of 2 degrees Celsius.

The most probable forecast for the development of the energy scenario and the reference one, taking into account the stabilization of climatic conditions, are presented in Figure 2 .

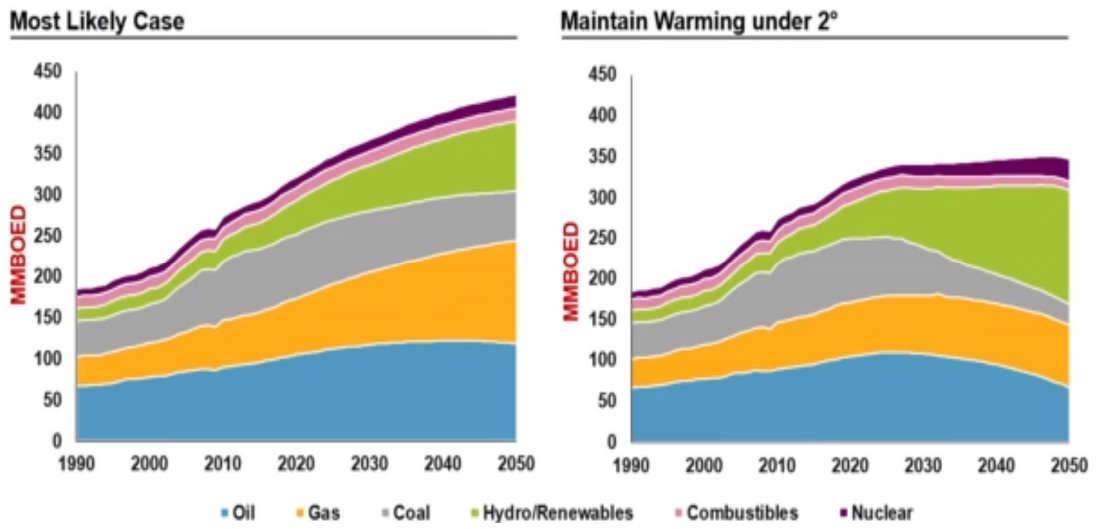

Fig. 2. Comparison of the likely scenario of energy consumption and the scenario taking into account the containment of the threshold value of warming at 2 degrees Celsius.

The opinion of energy producers should be taken into account. The behavior of energy corporations indicates that certain measures have been taken with regard to environmental and social risks. The potential technological development makes investors think about larger projects with a long-term effect. When expert agencies look at investment projects in the energy sector and evaluate them by credit rating, they take into account not only EBITDA, they try to determine the volatility of their future business. According to a study conducted by S\&P Global Platts over the past 2 years, it was revealed that in 700 examples of projects, environmental factors became drivers, 346 examples of projects proved to be effective due to social benchmarks. Among these examples, projects from sectors dominated: oil and gas, generation, and the mining and metallurgical industry. This is a pragmatic view of rating agencies that are increasingly considering environmental aspects. 
So there is an atlas of environmental factors where various sectors are evaluated depending on political and environmental risks. The most sensitive sectors are oil and gas, metals, generation. An assessment of companies' preparedness for environmental risk management showed that large energy corporations are sensitive to environmental aspects.

Despite the existing greenwashing on the market, it can be noted that all oil majors are increasingly investing in green energy in a larger volume. This is of great importance for their reputation in the world market, which is determined by the practice of policy disclosure. This is reflected in the Russian market, including in the transport sector. So, Russian Railways launched the project of new electric trains "Swallow". However, official data show that Russia is ranked 4th in the world ranking of $\mathrm{CO}_{2}$ emissions per capita. National goals are not that significant: a 30\% reduction in $\mathrm{CO}_{2}$ compared to 1990 .

Today, national projects are the most important vectors of the country's development. Among one of the significant for the energy sector is the national project "Ecology". In the course of project implementation, many questions arise, including on improving the passports of national projects and methods for their implementation.

Energy efficiency of the economy around the world is considered as the most important condition for energy and environmental security, sustainable economic development, and ensuring the competitiveness of national economies. Russia has to catch up with leading economies, whose energy intensity is $1.5-2$ times lower. According to international experts, Russia ranks 21 st in the list of energy-efficient economies. The ranking is led by Germany and Italy.

More than 10 years have passed since the signing of the Presidential Decree on some measures to increase the energy and environmental efficiency of the Russian economy and the goals have been set to reduce the energy intensity of the country's GDP by at least $40 \%$ by 2020 in relation to 2007 . This task is no longer feasible and has an adjustment. The energy strategy until 2030 sets ambitious goals to reduce the specific energy intensity of GDP by at least 2-3 times. In developing an action plan to limit energy consumption based on energy efficiency and energy saving in 2018, a new comprehensive plan for implementing measures to increase the energy efficiency of the economy of the Russian Federation was approved, which provides for a reduction in the energy intensity of the Russian economy due to the technological factor compared to the base year 2016 by 2025 by $25 \%$, and by 2030 by $23 \%$. A lot of by-laws and methodological documents in this area have been developed. However, significant changes have not yet occurred. The Ministry of Economic Development declares the lack of adequate data on the dynamics of energy intensity of GDP for previous years, which does not allow us to judge the progress in fulfilling the tasks. Thus, for the specified period, the strategic goal of the development of the national economy was not ensured - the formation of a system of indicators for monitoring the energy intensity of GDP and tracking its dynamics [6-10].

Russia, like all other exporting countries, also needs to consider the main challenges facing the energy sector. The search for stability in the oil market through active cooperation is a difficult task. The beneficiaries of cooperation are: producers, consumers, industry as a whole, which will attract investment and the stability of the financial system as a whole. The current situation in the energy market is not simple, despite the relative price stability, slight fluctuations in prices per barrel and relative price spike associated with the attack on two Saudi Aramco refineries in Saudi Arabia.

Part of the changes has been the rapid buildup of US oil, including shale oil.

Partnerships based on the created energy alliances began to play an important place, including $\mathrm{OPEC}+$, one of the most significant alliances. Alliances, which are supported by serious thinking and a look into the future of what can be done together, involve mutual trust, joint research, joint investment, cooperation in the energy and chemical industries. 
Such cooperation can lead to unlimited opportunities and the unification of forces in the energy sector.

There are many threats and uncertainties in the energy markets that can only be minimized by strong alliances. We give an example of uncertainty in the energy sector. In the summer, oil demand generally grows by about 2 million barrels per day worldwide, and during this period the reaction should be the pressure associated with an increase in productivity to meet growing demand. However, in 2019 this trend was not. There are also risks of going through the winter period when demand falls relative to the summer period. How the market will behave in the winter is currently quite difficult to predict. There are a lot of factors that affect the energy market, many of which are not obvious. In the last 2 years, the influence of factors such as trade wars between countries, which reduce consumption and increase uncertainty in the medium term, is noticeable. Another important factor in the development of the energy industry is geopolitics, including sanctions. Recent sanctions have been announced against China, which carries liquefied natural gas.

The fundamental factors determining the energy balance are completely obvious and understandable, however, they no longer have such significant weight in the energy market.

It is necessary to clearly coordinate and coordinate the activities of participants in energy alliances to level the volatility of energy markets.

The economic efficiency of Russian energy companies has radically changed, which indicates their competitiveness in the world market. Russia is one of the largest oil producing countries. Together, Russia, Saudi Arabia and the United States produce about 33 million barrels per year.

\section{Discussion}

The Russian energy industry has technological and infrastructural advantages that influence the advantages in pricing policy. However, there are also weaknesses, for example, expensive project financing. However, this is offset by other factors - an increase in the oil recovery coefficient in Western Siberia, a large production potential in the Arctic region, while the Arctic shelf with large reserves is still not fully explored. Therefore, the Russian energy sector over the long term plans to be one of the world leaders in the fuel and energy complex, taking into account competitive advantages and promising unrealized potential.

Consensus has been reached on many issues related to pressure at the regional and global levels. Much attention is paid to trends related to digitalization, climate measurement, demographic change, and fragmentation of political leadership.

Fragmentation of leadership at all levels in the energy sectors requires the formation of mechanisms to ensure dialogue between industries, governments for decisions affecting the future of energy. It is necessary to take into account all possible technologies that allow for the efficient development of the energy industry, taking into account restrictions and conditions on the world market. Energy security is paramount and determines the need to protect the industry from natural disasters and requires the development of information technology.

The peak demand is forecasted for the period from 2030 to 2040 for hydrocarbons, which requires providing how to reduce the hydrocarbon footprint of economies that are not electrified.

We live in a period of transition, when there is a concentration on the energy of natural gas and using renewable energy sources, which corresponds to the program of the Government of the Russian Federation. In the Arctic, the construction of three wind power parks is planned. Traditional energy and renewable energy should coexist, contributing to the diversification of the country's energy balance, as despite the fact that Russia has significant hydrocarbon reserves, balanced generation and energy consumption is the basis 
of energy development. One of the important support institutions is the Russian Direct Investment Fund, which helps to develop competition in the energy sectors.

The development of global energy alliances contributes not only to the economy of Saudi Arabia, but also to Russia (more than $\$ 100$ billion has been allocated to the Russian budget).

One can also single out the alliance of Total and NOVATEK companies, the principles of cooperation of which are based on three principles: trust; mutual respect between partners for what they can do, awareness of strengths and weaknesses; clear long-term shared vision. In 2011, Total, subject to the principles, provided a new level of investment in Russia in the amount of 12-13 billion dollars. This collaboration focuses on gas. The Arctic-LNG2 project is one of the results of the collaboration following the Yamal-LNG project. Total also concentrates on the largest LNG market in the world - Japan and the fastgrowing Chinese market (demand growth in China is $40 \%$ for 2017-2018). The Russian Federation is a region where the cost of LNG production is the lowest in the world. One of the priorities of the partnership is to create the conditions that meet the expectations for the transition to affordable, reliable and renewable clean energy.

In the context of climate change, Total declares a clean energy policy and has 5 goals. Active work is underway, including: the strategy is built around the scenario of the Paris climate agreement, for this there is a concentration of efforts on equipment, extraction and burning of associated gas, and gas development building up a business with low emissions (10\% of investments around the world are concentrated on energy with low emissions); use of competencies in the oil and gas industry; business development in the field of biofuels and work on the capture and storage of carbon emissions, as well as investments in agriculture and afforestation.

Active growth in the energy industry is taking place in the field of petrochemical production. One of the largest facilities in Russia will be the Amur Gas Processing Plant, which produces a sufficiently large amount of hydrocarbon feedstock for petrochemicals. The next step is to build a new production facility in partnership with the Russian company SIBUR and a gas company in the territory close to the target market of Southeast Asia. Russia is not the only country that implements such projects. There is a low growth in demand for motor fuel - about $1 \%$ annually, and a higher demand potential for petrochemical products, whose growth is slightly higher than the GDP growth rate. The competition between oil and gas companies that will sell their hydrocarbons through petrochemicals, entering into petrochemical refining projects, as well as investors who are looking for the cheapest sources of raw materials, is predicted to increase.

It should be borne in mind that the concept of sustainable development combines three key components: environment (ecology), social sphere and business. To achieve the goals of sustainable development, the triangle of these three elements must be equilateral, and only if equal efforts are made along the three coordinate axes, the global ecosystem can come to the target, balanced state. A global climate agenda is not feasible without nuclear energy, as nuclear generation is low-carbon and minimizes $\mathrm{CO}_{2}$ emissions into the atmosphere. Also, nuclear plants, being infrastructure projects of a national scale, have significant developmental effects for both the industrial sector and the local population.

\section{Conclusion}

If you apply a comprehensive business approach to solving existing problems, it is possible to ensure the effectiveness of the development of global energy. The development of international cooperation mechanisms, including alliances, helps stabilize energy markets in response to emerging challenges. 
Participation, at least as an observer, in the OPEC + alliance implies the joint development of various energy sectors, including petrochemical projects in the near future.

Alliances between energy market leaders in Russia and Saudi Arabia are needed in a turbulent geopolitically complex world. The formation of a powerful economic energy union and alliance has been ensured over 4 years of joint efforts aimed at developing relations based on trust.

Russia is opening new national projects to implement joint investments in projects supported by alliances.

Regarding world practice, it should be noted that over the past 8 years, energy generation from renewable energy sources has been significantly increased. The transformation of the energy sector, taking into account renewable energy sources, is proceeding in an active way, in view of the business effectiveness of such projects. The price of renewable energy is very low: 2 cents in the sun, 7 cents in the wind. The latest RES auction downwind showed 1.5 per $\mathrm{kW}$. This suggests that the construction of facilities using renewable energy will be more cost-effective than traditional. Of course, oil and gas will have a big role in the market. However, the current conditions and advantages of renewable energy sources make it possible to plan significant investment in new renewable energy projects - up to $\$ 180$ billion a year.

The basics of economic theory are that all corporations must use their competitive advantages. For Russia, this advantage is the supply of cheap energy. However, one should not rely solely on this advantage; it is necessary to ensure a differentiated approach to the energy sector and take into account global market trends.

\section{Reference}

1. BP, Energy Outlook: 2019 edition (BP p.l.c., London, 2018)

2. E.Ganebnykh, A. Mottaeva, T. Larinina, E.Petrova, MATEC Web of Conferences, 170, 01044 (2018) doi.org/10.1051/matecconf/201817001044

3. K. Locmelis, D. Blumberga, U. Bariss, Energy Procedia, 147, 202-206 (2018) doi.org/10.1016/j.buildenv.2018.02.012

4. P. Bertoldi, F. Diluiso, L. Castellazzi, N. Labanca, T. Serrenho, Energy Consumption and Energy Efficiency Trends in the EU-28 2000-2015 (Publications Office of the European Union, Italy, 2018) doi:10.2760/6684

5. I. Potekhin, V. Mischenko, A. Mottaeva, A. Zheltenkov, E3S Web of Conferences, 33, 03020 (2018) doi: 10.1051/e3sconf/20183303020

6. EEA, Trends and drivers in greenhouse gas emissions in the EU in 2016 (European Environment Agency, Copenhagen, 2018) doi:10.2800/691394

7. D. Zhikun, F. Ze, V.W.Y. Tam, B. Yu, L. Shenghan, I.M.C.S. Illankoon, M. Sungkon, Building and Environment, 133, 32-40 (2018) doi.org/10.1016/j.buildenv.2018.02.012

8. A. Bowen, K. Kuralbayeva, E.L.Tipoec, Energy Economics, 72, 263-275 (2018) https://doi.org/10.1016/j.eneco.2018.03.015

9. W.A. Pelser, J.C. Vosloo, M.J. Mathews, Journal of Cleaner Production, 198, 642-653 (2018) doi.org/10.1016/j.jclepro.2018.07.071

10. G. Ridauraa, S. Llorens-Cerveraa, C. Carrilloc, I. Buj-Corral, C. Riba-Romevaa, Resources, Conservation and Recycling, 131, 75-85 (2018) doi.org/10.1016/j.resconrec.2017.10.030 